\title{
Karin Lesnick-Oberstein: On Having an Own Child: Reproductive Technologies and the Cultural Construction of Childhood
}

\author{
Karnac Books, London, UK, 2008
}

\author{
Ruth Wittersgreen
}

Published online: 19 November 2009

(C) Springer Science+Business Media, LLC 2009

As reproductive technologies proliferate in our society, the implications of the use of such technologies demand to be explored. Lesnick-Oberstein most thoroughly examines the concept of an "own child," dismantling the desire for such as it has been explained biologically, socially, culturally, and historically. The author attempts to tease out meaning, questioning previous assumptions about why people want children. In her analysis, she draws from a variety of texts that address fertility/infertility and reproduction. From a philosophical and psychoanalytic framework, LesnickOberstein rigorously critiques the conclusions of earlier authors, highlighting many assumptions that have been seen as unquestionable, and invoking uncertainty and questioning about almost every imaginable concept related to reproduction. In the end, she concludes that there are no firm answers: the desire for an "own child" may not be innate and fixed, yet it is real to those who perceive it and will continue to drive reproductive technology.

Lesnick-Oberstein's book does what she set out to doto deeply analyze the assumptions regarding the biological and social drives to reproduce. She leaves "no stone unturned" as she plods through the writings of others, taking apart each statement, finding flaws in others' logic, revealing inherent contradictions, and elucidating the uncertainty that exists. Her work is undeniably an important contribution to the philosophical debates about assisted reproduction. What she does not do, and acknowledges not doing, is to examine personal narratives about infertility, the emotions involved, and the personal struggles inherent in this subject. Lesnick-Oberstein's book seems to attempt to divorce subjective experience from the topic in the service of providing some objective conclusions. What results is a book that seems to go in circles through a neverending maze of psychoanalytic and philosophical discourse, with little feeling and not much to offer on a practical level.

On Having an Own Child is a book that offers information which is of interest to many, but likely has a readership limited to those most concerned with the ethics, politics, or anthropological views of assisted reproduction. For a researcher or clinician dealing with the human struggle of infertility, or genetics and reproductive decision making, Lesnick-Oberstein's text is impractical in that it is quite dense and lacking insight that could translate into meaningful action. As the author states in her conclusion: [the book] "has not been about being able either to dispose of the own child, or of the reproductive technologies that are dedicated to producing it and are produced by it." The problems of reproduction are not going away, nor are the attempts to ameliorate the human suffering, albeit subjectively defined, that results from infertility/genetic problems. It would be useful to have more texts, perhaps expanding upon Lesnick-Oberstein's writing, detailing theories of what can be done to best shape decision making and influence practice with the emotional, subjective human beings who seek out reproductive technology. 